\title{
The influence of a distractor during compound preexposure on latent inhibition
}

\author{
PHIL REED and ELIAS TSAKANIKOS \\ University College London, London, England
}

\begin{abstract}
Nonreinforced exposure to a nontarget stimulus that was followed by nonreinforced exposure to a target/nontarget simultaneous compound stimulus resulted in enhanced latent inhibition of the target. Conditioning was slower after this treatment than after nonreinforced exposure to the target stimulus alone (Experiment 1). However, a salient auditory stimulus presented immediately after the compound in the second phase reduced levels of latent inhibition, relative to the enhanced latent inhibition produced when no such extracompound stimulus was presented (Experiments 2 and 3). This effect was not noted if the salient auditory cue was presented $10 \mathrm{sec}$ after the termination of the compound stimulus (Experiment 4). In Experiment 5, there was no disruption of simple latent inhibition produced by a salient stimulus. These results are consistent with enhanced latent inhibition's being produced by the formation of within-compound associations, which are disrupted by the salient extracompound stimuli.
\end{abstract}

Nonreinforced presentation of a stimulus (CS) retards subsequent acquisition of a conditioned response when that CS is paired with reinforcement (US); this phenomenon is referred to as latent inhibition or the CS-preexposure effect (see Hall \& Honey, 1988, and Lubow, 1989, for reviews). Some attempts to test between the various theories concerning the mechanisms underlying latent inhibition have focused on the ability of these theories to predict the effects of compound preexposure. In one follow-up set of studies, the effect of compound preexposure in a blocking design has been examined. That is, prior to conditioning with a target stimulus, subjects first are exposed to a nonreinforced nontarget stimulus and then are exposed to nonreinforced presentations of a simultaneous compound (target/nontarget) stimulus. These studies have produced a mixed set of findings: Honey and Hall (1988) reported no effects of this manipulation, whereas Reed (1995a, 1995b) noted that such a treatment resulted in enhanced levels of latent inhibition, relative to a group first exposed to the nontarget stimulus and then to the target stimulus prior to conditioning. This effect was termed enhanced latent inhibition.

Subsequent analysis of this finding has revealed that in order for the enhanced latent inhibition effect to be manifest, exposure to the nontarget stimulus in the first phase of this treatment has to be relatively extensive: 120 exposures produces the effect, whereas 80 or 40 exposures to the nontarget stimulus does not produce the effect (cf. Reed, 1991, 1995b). This effect of increasing the

These data were presented at the Experimental Analysis of Behaviour Group Meeting, London, 1998. Thanks are due Amanda Roberts and Julie DeJongh for help with collection of the data and Lisa A. Osborne for her comments and support. Correspondence concerning this article should be sent to P. Reed, Department of Psychology, University College London, Gower Street, London WC1E 6BT, England (e-mail: p.reed@ucl.ac.uk). number of nontarget preexposures can be observed, at least numerically, in the study reported by Honey and Hall (1988). Moreover, enhanced latent inhibition is obtained only if the two stimuli are presented in compound in the second phase of preexposure. Enhanced latent inhibition does not occur when the stimuli are presented randomly with respect to one another (Reed, 1995b; Reed, Anderson, \& Foster, 1999).

Reed (1995b) suggested that enhanced latent inhibition might be taken as support for a modified associative interference account of latent inhibition (see, e.g., Hall, Kaye, \& Pearce, 1985). This account suggests that during a standard stimulus preexposure procedure, subjects learn about a $C S-n o$-event relationship, which interferes with subsequent learning of a CS-US relationship (see also Killcross \& Balleine, 1996). This view accounts for the enhanced latent inhibition effect by suggesting that the blocking procedure is potentially also a higher order conditioning procedure (see also Schmajuk, Lam, \& Gray, 1996). If latent inhibition is a form of conditioning (and a CS-no-event association is learned during preexposure), some higher order conditioning of latent inhibition to the target stimulus might be expected by virtue of the target and nontarget stimuli's being paired during compound preexposure in Phase 2 (a nontarget-no-event association having been established in the first phase of the procedure). This higher order conditioning would lead to a greater level of target-no-event learning in subjects receiving this blocking treatment, since, for these subjects, there would be two sources from which such a noevent association could be formed-one direct and the other via the second-order association.

The explanation above of enhanced latent inhibition prompts the following question: Why does blocking not occur in stimulus preexposure paradigms, when it occurs readily in standard conditioning procedures? Holland 
(1980; see also Honey \& Hall, 1992) has shown that when no salient event follows a compound stimulus, within-compound associations are readily formed. When such a salient event, such as food or shock, follows a compound stimulus, the within-compound associations are disrupted. In a series of three experiments, Holland (1980) demonstrated that when a food US was presented immediately after a $\mathrm{CS}_{1}-\mathrm{CS}_{2}$ sequence, second-order conditioning between these stimuli was weaker than when no food followed that sequence. Similarly, the presentation of a surprising US following a $\mathrm{CS}_{1}-\mathrm{CS}_{2}$ sequence disrupted second-order conditioning more than did an expected US. This interference effect was attenuated when a temporal delay was imposed between the $\mathrm{CS}_{1}-\mathrm{CS}_{2}$ pairing and the surprising US presentation. In the case in which no salient event follows the pairing, as occurs in compound stimulus preexposure procedures, strong within-compound associations should favor the generation of second-order conditioning rather than blocking. If this argument is accepted, higher order conditioning might be expected to dominate any blocking effect in such a stimulus preexposure paradigm, leading to the production of enhanced latent inhibition.

In the present report, we explored whether disruption of the putative within-compound associations, which are taken to develop during the second phase of the exposure regime, could be produced in the stimulus pre-exposure procedure. This would extend the validation of the argument concerning the modified associative account of latent inhibition. Enhanced latent inhibition should be attenuated when second-order associations are attenuated. That is, under those conditions in which Holland (1980) noted weak second-order conditioning, there should also be weak enhanced latent inhibition. The present experiments should also produce corroborative evidence for the results reported by Holland and should further show the parallels between stimulus-event and stimulus-no-event learning.

\section{EXPERIMENT 1}

In the first experiment, we sought to demonstrate the basic enhanced latent inhibition effect under investigation (see Reed, 1995a). To this end, one group of subjects received a simple appetitive conditioning procedure, and another group of subjects received a simple latent inhibition treatment, by virtue of nonreinforced preexposure to the to-be-conditioned stimulus (i.e., $\mathrm{B}^{0}$ ). A third group of subjects received an enhanced latent inhibition treatment, being exposed first to a nontarget stimulus and then to a compound target/nontarget stimulus (i.e., $\left.\mathrm{A}^{0} / \mathrm{AB}^{0}\right)$. The latter subjects should show slower levels of conditioning than do the simple latent inhibition subjects (i.e., enhanced latent inhibition). A final group served to demonstrate that the enhanced latent inhibition effect depended on the influence of training in Phase 1. The subjects in the latter group were presented with a nonreinforced nontarget stimulus in Phase 1, followed by a compound stimulus comprising a target and a different nontarget stimulus in Phase 2 (i.e., $\mathrm{C}^{0} / \mathrm{AB}^{0}$ ).

\section{Method}

Subjects. Thirty-two experimentally naive male Sprague-Dawley rats were used in the present experiment. The subjects were all 4-5 months old at the start of the experiment, had a free-feeding body weight range of $335-455 \mathrm{~g}$, and were maintained at $85 \%$ of this weight throughout the experiment. The rats were housed in groups of 4 and had constant access to water in the home cage.

Apparatus. Training was conducted in four identical operantconditioning chambers (Camden Instruments), from which the levers had been withdrawn. The chambers were ventilated by a fan that also provided a $68-\mathrm{dB}(\mathrm{A})$ background masking noise. Reinforcement (one 45-mg food pellet) could be delivered to a food tray, which was covered by a clear Perspex hinged flap. A microswitch was operated when the flap was opened. A jeweled houselight $(2.8 \mathrm{~V})$, which served as the nontarget stimulus, was located in the center of the chamber ceiling. A second light $(2.8 \mathrm{~V})$, which served as the target stimulus and was placed so that it could illuminate the magazine tray from behind, was used as the target stimulus. A speaker was located on the ceiling of the chamber, through which a tone could be delivered (although this was not used in Experiment 1). The tone stimulus was a broadband signal, ranging up to $16 \mathrm{kHz}$, with peaks at $3 \mathrm{kHz}$ and $500 \mathrm{~Hz}$. It had an intensity of $88 \mathrm{~dB}(\mathrm{~A})$ - that is, $20 \mathrm{~dB}(\mathrm{~A})$ above background. Other than the visual stimuli, the chamber was not illuminated during the course of the experiment.

Procedure. The subjects were divided into four groups $(n=8)$. Phase 1 lasted for 12 sessions. During each of these sessions, Groups $\mathrm{C} / \mathrm{AB}$ and $\mathrm{A} / \mathrm{AB}$ were exposed to ten 30 -sec presentations of the nontarget (A) stimulus. For all the groups, the nontarget stimulus (A) was the overhead houselight. The first stimulus presentation occurred after $150 \mathrm{sec}$, and thereafter the mean interstimulus interval (ISI) was $150 \mathrm{sec}$. The other subjects received ten 30-min exposures to the context in the absence of any programmed events.

Phase 2 consisted of four sessions. During each session of Phase 2, Group A/AB received ten 30-sec exposures to a simultaneous compound comprising the target (illumination of the magazine light, in all cases) and the nontarget stimuli. Group B were exposed to ten $30-\mathrm{sec}$ presentations of the target stimulus. The remaining subjects received four 30 -min exposures to the context in the absence of any programmed events.

During conditioning sessions, all the groups received ten 30 -sec presentations of the target stimulus, followed immediately after its termination by reinforcement. The first trial occurred $150 \mathrm{sec}$ into the session; the ISI was $150 \mathrm{sec}$. There were four sessions of conditioning. The design of this experiment is represented schematically in Table 1.

\section{Results and Discussion}

Figure 1 displays the group-mean elevation ratios for the four sessions of conditioning. The elevation ratio was calculated by counting the total number of magazine entries made during the CS period and dividing this number by the sum of the magazine entries made during the CS period and the $30-\mathrm{sec}$ period prior to the CS. Inspection of these data reveals that all the groups acquired the conditioned response but that they did so at different rates from one another. Group Cond displayed more conditioned responding than did Group B, and this group displayed higher levels of conditioned responding than did Group A/AB. Levels of conditioning in Group C/AB were similar to those in Group Cond. 
Table 1

Schematic Representation of the Design of all Five Experiments

\begin{tabular}{|c|c|c|c|}
\hline Group & $\begin{array}{c}\text { Phase } 1 \\
\text { Preexposure }\end{array}$ & $\begin{array}{c}\text { Phase } 2 \\
\text { Preexposure }\end{array}$ & $\begin{array}{c}\text { Phase } 3 \\
\text { Acquisition }\end{array}$ \\
\hline \multicolumn{4}{|c|}{ Experiment 1} \\
\hline Cond & & & $\mathrm{B}+$ \\
\hline B & & B & $\mathrm{B}+$ \\
\hline $\mathrm{A} / \mathrm{AB}$ & A & $\mathrm{AB}$ & $\mathrm{B}+$ \\
\hline $\mathrm{C} / \mathrm{AB}$ & $\mathrm{C}$ & $\mathrm{AB}$ & $\mathrm{B}+$ \\
\hline \multicolumn{4}{|c|}{ Experiment 2} \\
\hline $\mathrm{A} / \mathrm{AB}$ & A & $\mathrm{AB}$ & $\mathrm{B}+$ \\
\hline $\mathrm{A} / \mathrm{AB}^{\mathrm{IC}}$ & A & $\mathrm{AB} \rightarrow$ Tone & $\mathrm{B}+$ \\
\hline $\mathrm{A} / \mathrm{A}^{0} \mathrm{~B}^{0}$ & A & A, B & $\mathrm{B}+$ \\
\hline \multicolumn{4}{|c|}{ Experiment 3} \\
\hline $\mathrm{A} / \mathrm{AB}$ & $\mathrm{A}$ & $\mathrm{AB}$ & $\mathrm{B}+$ \\
\hline $\mathrm{A} / \mathrm{B}$ & A & B & $\mathrm{B}+$ \\
\hline $\mathrm{A} / \mathrm{AB}^{\mathrm{C}}$ & A & $\mathrm{AB} \rightarrow$ Tone & $\mathrm{B}+$ \\
\hline $\mathrm{A} / \mathrm{AB}^{-\mathrm{C}}$ & A & $\mathrm{AB} \longrightarrow \longrightarrow$ Tone & $\mathrm{B}+$ \\
\hline \multicolumn{4}{|c|}{ Experiment 4} \\
\hline $\mathrm{A} / \mathrm{AB}$ & A & $\mathrm{AB}$ & $\mathrm{B}+$ \\
\hline $\mathrm{A} / \mathrm{AB}^{\mathrm{C}}$ & A & $\mathrm{AB} \rightarrow$ Tone & $\mathrm{B}+$ \\
\hline $\mathrm{A} / \mathrm{AB}-\mathrm{C}$ & A & $\mathrm{AB} \longrightarrow \longrightarrow$ Tone & $\mathrm{B}+$ \\
\hline \multicolumn{4}{|c|}{ Experiment 5} \\
\hline $\mathrm{A} / \mathrm{AB}^{\mathrm{C}}$ & $\mathrm{A}$ & $\mathrm{AB} \rightarrow$ Tone & $\mathrm{B}+$ \\
\hline $\mathrm{A} / \mathrm{B}^{\backslash \mathrm{C}}$ & $\mathrm{A}$ & $\mathrm{B} \rightarrow$ Tone & $\mathrm{B}+$ \\
\hline $\mathrm{A} / \mathrm{AB}^{\backslash \mathrm{C}}$ & $\mathrm{A}$ & $\mathrm{AB}$, Tone & $\mathrm{B}+$ \\
\hline $\mathrm{A} / \mathrm{B}^{\backslash \mathrm{C}}$ & A & B, Tone & $\mathrm{B}+$ \\
\hline
\end{tabular}

These data were subjected to a two-factor analysis of variance (ANOVA), with group and session as factors. A rejection criterion of $p<.05$ was adopted for this and all subsequent analyses. This ANOVA revealed significant main effects of group $\left[F(3,28)=11.26, M S_{\mathrm{e}}=0.03\right]$ and session $\left[F(3,84)=35.81, M S_{\mathrm{e}}=0.01\right]$ and a statistically significant interaction between the two factors $[F(9,84)=$ $\left.3.07, M S_{\mathrm{e}}=0.01\right]$. To further analyze the interaction, the simple effect of group at each session was analyzed. These analyses revealed a significant simple effect of group on Sessions 3 and 4 [smallest $F(3,98)=10.07$ ]. Tukey's honestly significant difference (HSD) tests were conducted on these later sessions. These tests revealed significant pairwise differences between Group $\mathrm{A} / \mathrm{AB}$ and all the other groups and between Groups B and Cond on Session 3. On Session 4, all pairwise comparisons were significant, except that between Group Cond and Group C/AB.

To ensure that use of the elevation ratio was appropriate, the mean number of responses in the pre-CS periods for each session (i.e., background response rate) was calculated and subjected to a two-factor ANOVA (group $\times$ block). This analysis revealed no statistically significant difference between the groups $(F<1)$; neither was the group $\times$ session interaction significant $(F<1)$. Thus, there were no statistically significant differences in the background rate of responding.

These results demonstrate the enhanced latent inhibition effect obtained in previous studies (Reed, 1995a; Reed, Petrochilos, Upal, \& Baum, 1997). That is, a blocking design does not reduce the extent to which latent inhibition is found but makes the stimulus preexposure effect somewhat larger than it would be otherwise. That the effect is dependent on some transfer of training from Phase 1 to Phase 2 is suggested by the results from the group that received exposure to a nontarget stimulus that

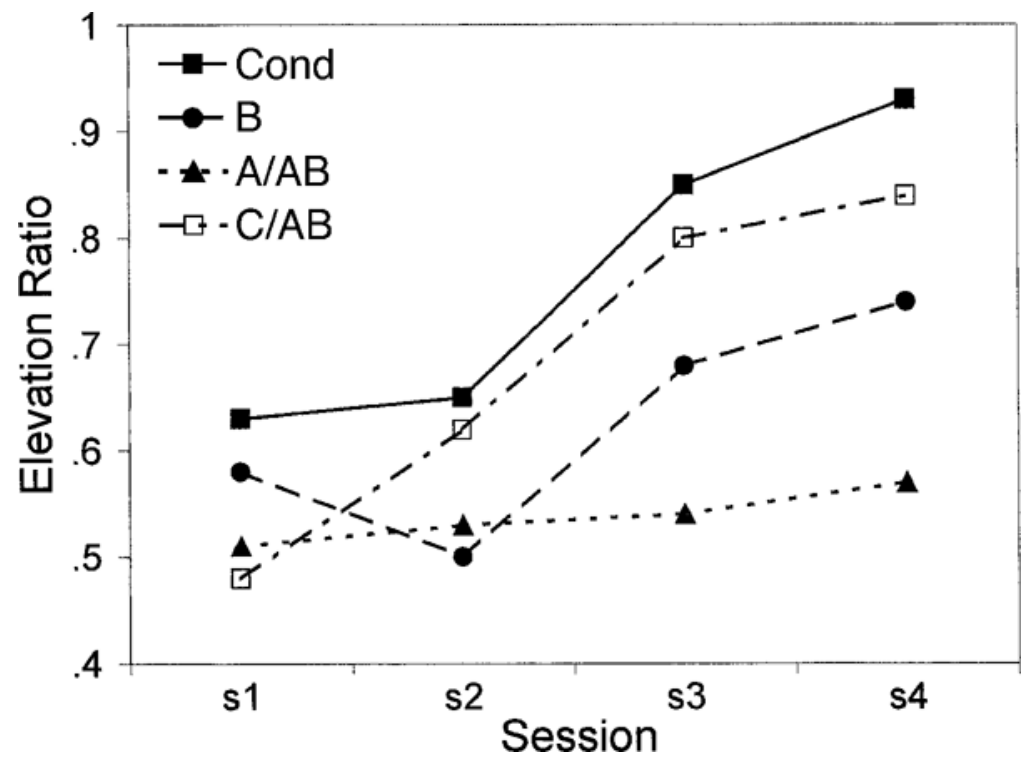

Figure 1. Results from Experiment 1: group-mean elevation ratios averaged over each session. Group A/AB received exposure to the nontarget stimulus before exposure to a target/nontarget simultaneous compound stimulus prior to conditioning. Group $A / A B^{C}$ received exposure to the nontarget stimulus before exposure to a target/nontarget simultaneous compound stimulus, followed by a tone, prior to conditioning. Group B received exposure to the target stimulus prior to conditioning. Group Cond received no preexposure prior to conditioning. 
did not form part of the nonreinforced compound in Phase 2 . These subjects responded at a relatively high rate, similar to a conditioning group. This is not surprising, since if there is little transfer between the phases, this group is essentially an overshadowing of the latent inhibition group (see Reed, 1991).

This enhanced latent inhibition effect is not predicted by many accounts of latent inhibition. For example, Lubow's (1989) conditioned attention theory makes the opposite prediction regarding the effect on latent inhibition of such a blocking procedure. On the other hand, the modified associative view does predict this pattern of results. This view would suggest that there are two sources of B-no-event learning in the group exposed to the blocking design-one direct and the other mediated through a second-order association of the target to the nontarget stimulus.

\section{EXPERIMENT 2}

The present experiment compared the effects of three stimulus preexposure treatments on subsequent conditioning. The first group of rats received the enhanced latent inhibition exposure treatment described above (i.e., $\left.\mathrm{A}^{0} / \mathrm{AB}^{0}\right)$. The second group of subjects received exposure to the nontarget stimulus (A), followed by exposure to both the nontarget (A) and the target (B) stimuli, but not in compound with each other (i.e., $\mathrm{A}^{0} / \mathrm{A}^{0} \mathrm{~B}^{0}$ ). Levels of conditioning to the target (B) should be lower in the former group than in the latter if the enhanced latent inhibition effect, reported previously, is to be confirmed. A third group of rats received the enhanced latent inhibition treatment, with the addition of a salient auditory stimulus (C), presented immediately following the com-

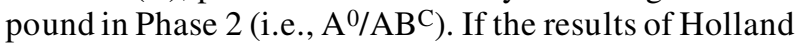
(1980) were to be extended to the present paradigm, presentation of such a stimulus (C) following the compound (AB) should disrupt the formation of within-compound associations. This disrupter should prevent the formation of strong second-order associations between $\mathrm{B}$ and $\mathrm{A}$ and should reduce the extent to which B becomes associated with no event as a result of such conditioning. In turn, this should lead to a lesser degree of latent inhibition (i.e., greater levels of conditioning) when B is subsequently conditioned.

\section{Method}

Subjects and Apparatus. Twenty-four experimentally naive male Sprague-Dawley rats were used in the present experiment. The subjects were all 4-5 months old at the start of the experiment, had a free-feeding body weight range of 330-485 g, and were maintained as described in Experiment 1. The apparatus was that described in Experiment 1.

Procedure. The subjects were divided into three equal groups $(n=8)$. Phase 1 lasted for 12 sessions. During each of these sessions, all the groups were exposed to ten 30 -sec presentations of the nontarget (A) stimulus. For all the groups, the nontarget stimulus (A) was the overhead houselight. The first stimulus presentation occurred after $150 \mathrm{sec}$, and thereafter, the mean ISI was $150 \mathrm{sec}$.
Phase 2 consisted of four sessions. During each session of Phase 2, Group A/AB received ten $30-\mathrm{sec}$ exposures to a simultaneous compound comprising the target (illumination of the magazine light) and the nontarget (houselight) stimuli. Group $\mathrm{A} / \mathrm{AB}^{\mathrm{C}}$ similarly was exposed to a simultaneous compound, comprising the target and nontarget stimuli. However, each time the compound stimulus was terminated, this group received a 2 -sec presentation of the auditory stimulus (tone). Group $\mathrm{A} / \mathrm{A}^{0} \mathrm{~B}^{0}$ received four sessions of nonreinforced exposure to both stimuli, but presented separately from one another. Thus, in a session, the subjects in Group A/A ${ }^{0} \mathrm{~B}^{0}$ received ten 30 -sec exposures to the overhead light stimulus and ten 30 -sec exposures to the magazine light stimulus (for Group $\mathrm{A} / \mathrm{A}^{0} \mathrm{~B}^{0}$, the two stimuli were on independent fixed-time, 75 -sec schedules of presentation). The first stimulus presentation for the above three groups occurred $150 \mathrm{sec}$ into the session; all the subsequent ISIs were $150 \mathrm{sec}$, except for Group $\mathrm{A} / \mathrm{A}^{0} \mathrm{~B}^{0}$, for which the ISI was $75 \mathrm{sec}$.

During conditioning sessions, all groups received ten 30 -sec presentations of the target stimulus, followed immediately after its offset by reinforcement. The first trial occurred $150 \mathrm{sec}$ into the session, and the ISI was $150 \mathrm{sec}$. There were four sessions of conditioning.

\section{Results and Discussion}

Figure 2 displays the group-mean elevation ratios for the four sessions of conditioning. The elevation ratio was calculated as described in Experiment 1. Inspection of these data reveals that all the groups acquired the conditioned response but that they did so at different rates from one another. Groups $\mathrm{A} / \mathrm{A}^{0} \mathrm{~B}^{0}$ and $\mathrm{A} / \mathrm{AB}^{\mathrm{C}}$ typically displayed more conditioned responding than did Group $\mathrm{A} / \mathrm{AB}$.

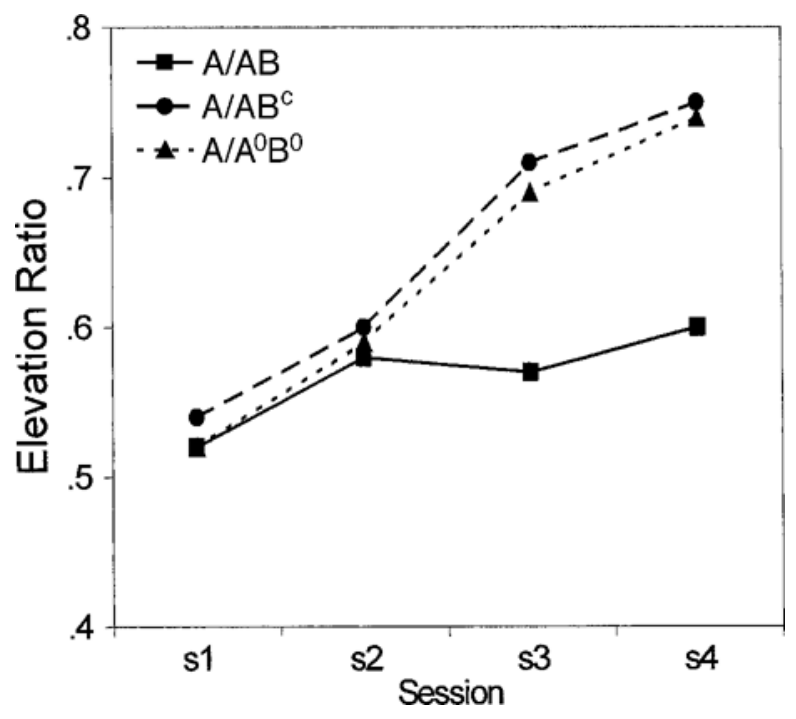

Figure 2. Results from Experiment 2: group-mean elevation ratios averaged over each session. Group A/AB received exposure to the nontarget stimulus before exposure to a target/nontarget simultaneous compound stimulus prior to conditioning. Group $A / A^{C}$ received exposure to the nontarget stimulus before exposure to a target/nontarget simultaneous compound stimulus, followed by a tone, prior to conditioning. Group $A / A^{0} B^{0}$ received exposure to the nontarget stimulus, then to the nontarget and target stimuli separately from one another. 
These data were subjected to a two-factor ANOVA (group $\times$ session) that revealed no main effect of group $(F<1)$ but a significant main effect of session $[F(3,63)=$ 6.08, $\left.M S_{\mathrm{e}}=0.01\right]$ and a significant interaction between the two factors $\left[F(6,63)=5.56, M S_{\mathrm{e}}=0.01\right]$. An analysis of the simple effect of group on each session revealed a significant difference between the groups on Session 3 $[F(2,34)=2.25]$ and on Session $4[F(2,34)=6.00]$. On both of these sessions, Tukey's HSD tests revealed that Groups $A / A^{0} B^{0}$ and $A / A B^{C}$ each had higher elevation ratios than did Group $A / A B$.

To ensure that use of the elevation ratio was appropriate, the mean number of responses in the pre-CS periods for each session (i.e., background response rate) was calculated and subjected to a two-factor ANOVA (group $\times$ block). This analysis revealed no statistically significant difference between the groups $(F<1)$; neither was the group $\times$ session interaction significant $(F<1)$. Thus, there were no statistically significant differences in the background rate of responding; these scores were 1.9 for Group $\mathrm{A} / \mathrm{AB}, 2.4$ for Group $\mathrm{A} / \mathrm{AB}^{\mathrm{C}}$, and 2.3 for Group $\mathrm{A} / \mathrm{A}^{0} \mathrm{~B}^{0}$.

The modified associative interference account appears to be corroborated by the present results with respect to the effect of the salient extracompound stimulus. When a salient stimulus was presented following the compound stimulus in Phase 2, subsequent conditioning of the target proceeded more rapidly than when the salient stimulus was not presented following the compound. According to the results of Holland (1980), presentation of such a salient stimulus following a compound stimulus should disrupt the formation of within-compound associations. If this disruption of within-compound associations had occurred in the present experiment, less latent inhibition might have been predicted for the group with the extracompound tone, relative to that noted in the standard enhanced latent inhibition treatment. In the former group, there would be a weaker B-A association (owing to disruption of the within-compound associations), which would lead to less conditioning of B to no event, via a second-order association through the nontarget (A).

\section{EXPERIMENT 3}

Since the results from the preceding experiment had some importance for the various theories concerning latent inhibition, it seemed important to illuminate the basis of enhanced latent inhibition and its disruption. To this end, Experiment 3 included two of the groups from Experiment $2\left(\mathrm{~A} / \mathrm{AB}\right.$ and $\left.\mathrm{A} / \mathrm{AB}^{\mathrm{C}}\right)$ in order to corroborate that the extracompound stimulus would disrupt the enhanced latent inhibition. A group receiving exposure to the nontarget (A) prior to exposure to the target (B) was included to establish the presence of enhanced latent inhibition (A/B). In addition, a fourth group, included by Holland (1980) in the study of the effects of salient stimuli on within-compound associations, was included in the present study. This group received the salient extracompound cue following the compound, as for the above $\mathrm{A} / \mathrm{AB}^{\mathrm{C}}$ group, but the presentation of the extra stimulus (C) was delayed by $5 \mathrm{sec}$ following the compound termination. In the study reported by Holland, such a temporal delay between the compound and the following salient stimulus was sufficient to attenuate the disruptive effect of the extracompound stimulus. If such an effect were to be noted in the present procedure, the fourth group $\left(\mathrm{A} / \mathrm{AB}^{-\mathrm{C}}\right)$ should show levels of latent inhibition similar to those for the group not receiving the cue.

\section{Method}

Subjects. Thirty-two experimentally naive male Sprague-Dawley rats served in the present experiment. All the rats were 3-4 months old at the start of the study, had a free-feeding body weight range of $325-430 \mathrm{~g}$, and were maintained as described in Experiment 1. The apparatus was that described in Experiment 1.

Procedure. The procedure for Groups $\mathrm{A} / \mathrm{AB}$ and $\mathrm{A} / \mathrm{AB}^{\mathrm{C}}$ was identical to that described in Experiment 2. Group A/AB-C received identical treatment to that described for Group $A / \mathrm{AB}^{\mathrm{C}}$, except that the extracompound stimulus (C) was presented $5 \mathrm{sec}$ after the termination of the compound stimulus $(\mathrm{AB})$ in Phase 2. Group $\mathrm{A} / \mathrm{B}$ received the same Phase 1 treatment as all of the other groups, but in Phase 2 received only the presentations of the target stimulus (B). All other details of the experimental procedure were as described in Experiment 2.

\section{Results and Discussion}

Figure 3 displays the group-mean elevation ratios for each session during conditioning. The elevation ratio was calculated as described in Experiment 1. Inspection of these data reveals that all the groups acquired the conditioned response over the course of training. However, Group $\mathrm{A} / \mathrm{AB}^{\mathrm{C}}$ had the highest elevation ratio of all the four groups, followed by Group $\mathrm{A} / \mathrm{AB}^{-\mathrm{C}}$. By the end of training, Group A/B had a greater elevation ratios than Group $\mathrm{A} / \mathrm{AB}$, which had the lowest elevation ratio of all four groups.

These data were subjected to a two-factor ANOVA (group $\times$ block), which revealed a statistically significant main effect of group $\left[F(3,28)=3.58, M S_{\mathrm{e}}=0.02\right]$ and a significant main effect of session $[F(3,84)=16.15$, $\left.M S_{\mathrm{e}}=0.01\right]$ but no significant interaction between the two factors $(F<1)$. Owing to the absence of an interaction, these data were collapsed across sessions, and this procedure revealed group-mean elevation ratios of .54 for Group A/AB, .62 for Group A/B, .67 for Group $\mathrm{A} / \mathrm{AB}^{\mathrm{C}}$, and .63 for Group $\mathrm{A} / \mathrm{AB}^{-\mathrm{C}}$. Tukey's HSD tests conducted on these group means revealed that Groups $\mathrm{A} / \mathrm{B}, \mathrm{A} / \mathrm{AB}^{\mathrm{C}}$, and $\mathrm{A} / \mathrm{AB}^{-\mathrm{C}}$ each had a higher elevation ratio than did Group $A / A B$ but that no other pairwise differences were significant.

To ensure that use of the elevation ratio was appropriate, the mean number of responses in the pre-CS periods for each session (i.e., background response rate) was calculated. These scores were subjected to a two-factor 


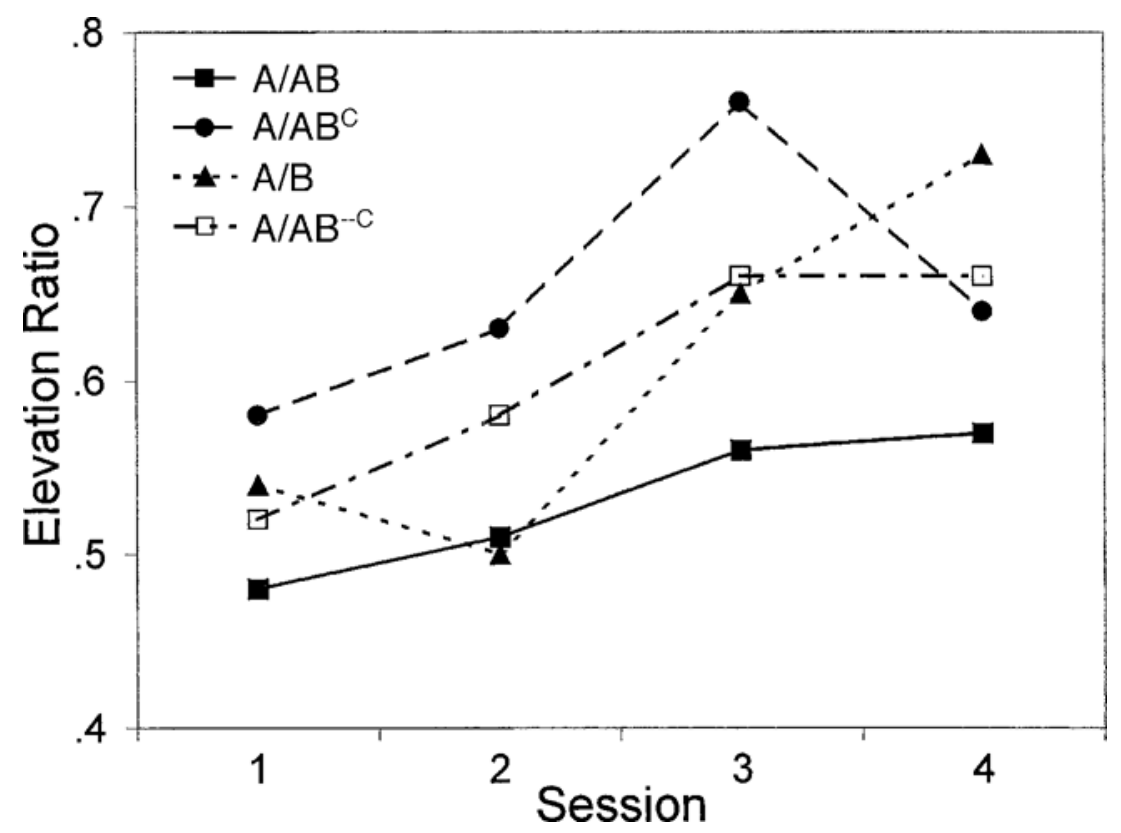

Figure 3. Results from Experiment 3: group-mean elevation ratios averaged over each session. Group A/A B received exposure to the nontarget stimulus before exposure to a target/ nontarget simultaneous compound stimulus prior to conditioning. Group $A / A B^{C}$ received exposure to the nontarget stimulus before exposure to a target/nontarget simultaneous compound stimulus, followed by a tone, prior to conditioning. Group A/B received exposure to the nontarget stimulus, then to the target stimulus. Group $\mathrm{A} / \mathrm{AB}^{-\mathrm{C}}$ received exposure to the nontarget stimulus before exposure to a target/nontarget simultaneous compound stimulus, followed $5 \mathrm{sec}$ later by a tone, prior to conditioning.

ANOVA (group $\times$ block). This analysis revealed no statistically significant difference between the groups $(F<$ $1)$; neither was the group $\times$ session interaction significant $(F<1)$. Thus, there were no statistically significant differences in the background rate of responding in this experiment. The mean rate of responding in the pre-CS periods, collapsed over all sessions, was 1.9 for Group $\mathrm{A} / \mathrm{AB}, 1.9$ for Group $\mathrm{A} / \mathrm{AB}^{\mathrm{C}}, 2.1$ for Group $\mathrm{A} / \mathrm{B}$, and 2.6 for Group $\mathrm{A} / \mathrm{AB}^{-\mathrm{C}}$.

These results confirm that enhanced latent inhibition can be obtained relative to a simple latent inhibition control; Group A/AB had a lower elevation ratio than did Group A/B (Reed, 1995a). Also, presentation of a salient cue following a compound stimulus attenuates the level of latent inhibition observed following an enhanced latent inhibition exposure procedure. This aspect of the result replicates the finding reported in Experiment 2 and provides some confirmation of the predictions from the modified associative view of latent inhibition (Reed, 1995a). However, delaying the presentation of the salient cue following offset of the compound stimulus by $5 \mathrm{sec}$ did not appear to have any effect on the attenuation of enhanced latent inhibition. The group that received the delayed extracompound stimulus conditioned as rapidly as the group that received the immediate extracompound stimulus. These results are not predicted by the modified associative view outlined above and do not appear to fol- low the pattern of results reported by Holland (1980). In the latter study, such a delayed stimulus did not disrupt the formation of within-compound associations (or the within-compound view may be incorrect). The modified associative interference view of latent inhibition suggests, on this basis, that the delayed-stimulus treatment condition would not attenuate the enhanced latent inhibition effect, since it would not disrupt the within-compound cues, and it would leave the second-order B-A association intact during Phase 2.

\section{EXPERIMENT 4}

It could be, of course, that the 5-sec delay between the compound stimulus termination and the presentation of the extracompound salient stimulus in the present Experiment 3 was not long enough for the effects of a particularly loud salient disrupter to be dissipated. To establish whether or not the delay of $5 \mathrm{sec}$ was too short to terminate the disruptive effect of the stimulus, in Experiment 4 a 10 -sec delay between the compound termination and the presentation of the disrupter stimulus was used. If such a delay were to be effective in attenuating the effects of the extracompound cue, the group receiving this stimulus $(A / A B-C)$ should show levels of latent inhibition similar to those of the group not receiving the cue $(\mathrm{A} / \mathrm{AB})$ and should condition less quickly than a 
group receiving a stimulus immediately on termination of the compound $\left(\mathrm{A} / \mathrm{AB}^{\mathrm{C}}\right)$.

\section{Method}

Subjects. Twenty-four experimentally naive male Sprague-Dawley rats served in the present experiment. All the rats were 3-4 months old at the start of the study, had a free-feeding body weight range of $345-415 \mathrm{~g}$, and were maintained as described in Experiment 1. The apparatus was that described in Experiment 1.

Procedure. The procedure for Groups $\mathrm{A} / \mathrm{AB}$ and $\mathrm{A} / \mathrm{AB}^{\mathrm{C}}$ was identical to that described in Experiment 3. Group $A / A B-C$ received identical treatment to that described for Group A/ABC, except that the extracompound stimulus (C) was presented $10 \mathrm{sec}$ after the termination of the compound stimulus (AB) in Phase 2. With the exception of the omission of Group A/B, all other details of the experimental procedure were as described in Experiment 2.

\section{Results and Discussion}

Figure 4 displays the group-mean elevation ratios for each session during conditioning. The elevation ratio was calculated as described in Experiment 1. Inspection of these data reveals that all the groups acquired the conditioned response but that, by the end of training, Group $\mathrm{A} / \mathrm{AB}^{\mathrm{C}}$ had a greater elevation ratio than did either Group A/AB or Group A/AB - C.

These data were subjected to a two-factor ANOVA (group $\times$ block), which revealed no statistically significant main effect of group $(F<1)$ but a significant main effect of session $\left[F(3,63)=12.30, M S_{\mathrm{e}}=0.01\right]$ and a marginally significant interaction between the two fac- tors $\left[F(6,63)=2.00, M S_{\mathrm{e}}=0.01, .08>p>.07\right]$. An analysis of the simple effect of group on each session revealed a significant difference on Sessions 3 and 4 [smallest $F(3,63)=2.23$ ]. Tukey's HSD tests conducted on these sessions revealed that both Group $\mathrm{A} / \mathrm{AB}$ and Group $A / A B-C$ differed from Group $A / A B^{C}$. No other pairwise differences were significant.

To ensure that use of the elevation ratio was appropriate, the mean number of responses in the pre-CS periods for each session (i.e., background response rate) was calculated. These scores were subjected to a two-factor ANOVA (group $\times$ block). This analysis revealed no statistically significant difference between the groups $(F<$ $1)$; neither was the group $\times$ session interaction significant $(p>.30)$. Thus, there were no statistically significant differences in the background rate of responding in this experiment. The mean rates of responding in the pre-CS periods, collapsed over all sessions, were 1.1 for Group $\mathrm{A} / \mathrm{AB}, 1.2$ for Group $\mathrm{A} / \mathrm{AB}^{\mathrm{C}}$, and 1.1 for Group $\mathrm{A} / \mathrm{AB}-\mathrm{C}$.

These results confirm that presentation of a salient cue following a compound stimulus attenuates the level of latent inhibition noted following an enhanced latent inhibition exposure procedure. However, delaying the presentation of the salient cue following offset of the compound stimulus by $10 \mathrm{sec}$ was enough to attenuate the effect of the salient stimulus; latent inhibition appeared to accrue just as strongly in a group that received

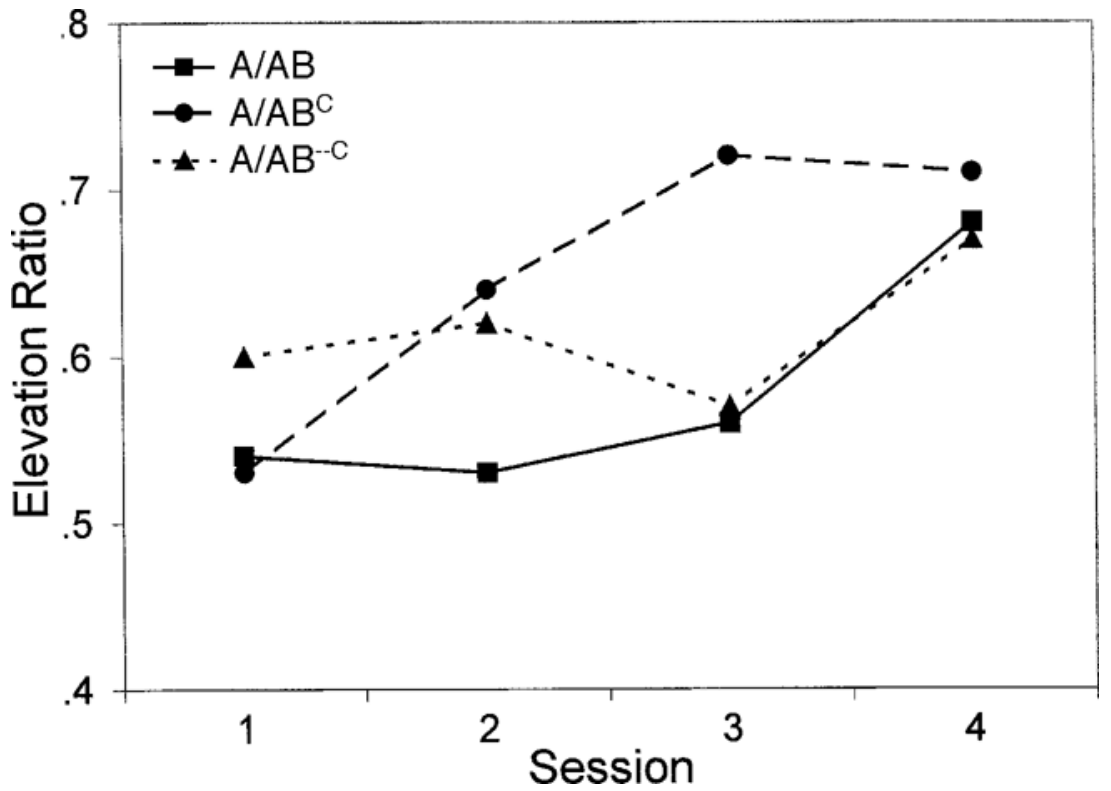

Figure 4. Results from Experiment 4: group-mean elevation ratios averaged over each session. Group A/AB received exposure to the nontarget stimulus before exposure to a target/nontarget simultaneous compound stimulus prior to conditioning. Group $A / A_{B}$ received exposure to the nontarget stimulus before exposure to a target/nontarget simultaneous compound stimulus, followed by a tone, prior to conditioning. Group $\mathrm{A}^{-\mathrm{AB}^{-\mathrm{C}}}$ received exposure to the nontarget stimulus before exposure to a target/nontarget simultaneous compound stimulus, followed $10 \mathrm{sec}$ later by a tone, prior to conditioning. 
this delayed extracompound cue as it did in a group not receiving the extracompound stimulus. The results from this experiment suggest that the delay between the compound stimulus $(\mathrm{AB})$ and the salient stimulus $(\mathrm{C})$ used in the present Experiment 3 was not long enough for the effects of the salient disrupter to be dissipated. The 10-sec delay used in Experiment 4, on the other hand, appeared to be long enough that any disruptive effect of the extracompound stimulus was attenuated. The difference in the length of time needed to overcome the within-compound disruption between the present report and that noted by Holland (1980) more than probably reflects the very different procedures involved: second-order conditioning in the study by Holland stimulus preexposure in the present report.

\section{EXPERIMENT 5}

In the previous experiments, it has been suggested that a salient event presented after a nonreinforced compound stimulus disrupted the formation of within-compound associations. This disruption presumably limited the growth of a target-no-event association by reducing the strength of the second-order association between the target and the no-event representation mediated through the target-nontarget association. However, it should be noted that the designs used in the previous experiments do not necessarily show that the distractor specifically affects the target-nontarget association. It could be that the salient cue would reduce latent inhibition when presented after the target stimulus alone (i.e., $\mathrm{B}^{\mathrm{C}}$ ). If the salient cue disrupts simple latent inhibition, as it sometimes does (Lubow, Schnur, \& Rifkin, 1976), there would be no need to appeal to the disruption of within-compound associations to explain the results reported above.

To test this possibility, the present experiment employed four groups: an enhanced latent inhibition group $(A / A B \backslash C)$, a disruption of enhanced latent inhibition group $\left(\mathrm{A} / \mathrm{AB}^{\mathrm{C}}\right)$, a simple latent inhibition group $\left(\mathrm{A} / \mathrm{B}^{\backslash \mathrm{C}}\right)$, and a group to assess the effect of a salient cue (C) following the target in simple latent inhibition $\left(\mathrm{A} / \mathrm{B}^{\mathrm{C}}\right)$. To assess the degree to which the salient cue disrupted performance per se, the standard latent inhibition and enhanced latent inhibition groups had the same number of salient cues as that received by the two disrupted groups presented during Phase 2, but the salient cues were presented randomly with respect to the target stimulus or compound. If the salient cue disrupts enhanced latent inhibition owing to its impact on within-compound associations, Group A/AB ${ }^{\backslash C}$ should show the lowest levels of conditioning, with all of the other groups showing higher levels of conditioning than does this group.

\section{Method}

Subjects and Apparatus. Forty-eight experimentally naive male Sprague-Dawley rats served in the present experiment. All the rats were 3-4 months old at the start of the study, had a free-feeding body weight range of 360-450 g, and were maintained as described in Experiment 1. The apparatus was that described in Experiment 1.

Procedure. The procedure for Groups $\mathrm{A} / \mathrm{AB}^{\mathrm{C}}$ was identical to that described in Experiment 2. Group $A / \mathrm{B}^{\mathrm{C}}$ received treatment identical to that of the former group, except that only the target stimulus was presented, followed by the salient cue, during Phase 2. Groups $\mathrm{A} / \mathrm{AB}^{\backslash \mathrm{C}}$ and $\mathrm{A} / \mathrm{B}^{\backslash \mathrm{C}}$ received treatment identical to that described for Groups $\mathrm{A} / \mathrm{AB}^{\mathrm{C}}$ and $\mathrm{A} / \mathrm{B}^{\mathrm{C}}$, respectively, except that the 2 -sec extracompound stimulus (C) was on a variable-time 180-sec schedule, with the constraint that there were 10 presentations of this stimulus per session. All other details of the procedure were as described in Experiment 2, except that there were six conditioning sessions.

\section{Results and Discussion}

Figure 5 displays the group-mean elevation ratios for each session during conditioning. The elevation ratio was calculated as described in Experiment 1. Inspection of these data reveals that all the groups acquired the conditioned response over the course of training but did so at different rates. Group $\mathrm{A} / \mathrm{AB}{ }^{\backslash \mathrm{C}}$ had the lowest elevation ratio of all four groups in the experiment, with the other groups coming to have similar rates to each other by the end of training.

These data were subjected to a two-factor ANOVA (group $\times$ block), which revealed a statistically significant main effect of group $\left[F(3,43)=3.81, M S_{\mathrm{e}}=0.06\right]$ and a significant main effect of session $[F(5,215)=17.04$, $\left.M S_{\mathrm{e}}=0.02\right]$ but no significant interaction between the two factors $(p<.10)$. The elevation ratios were collapsed across the sessions. This produced mean elevation ratios of .53 for Group $\mathrm{A} / \mathrm{AB}^{\backslash \mathrm{C}}, .60$ for Group $\mathrm{A} / \mathrm{AB}^{ }{ }^{\mathrm{C}}, .64$ for Group $\mathrm{A} / \mathrm{B}^{\backslash \mathrm{C}}$, and .64 for Group $\mathrm{A} / \mathrm{B}^{\mathrm{C}}$. Tukey's HSD tests revealed that Group $\mathrm{A} / \mathrm{AB}^{\backslash \mathrm{C}}$ had a lower elevation ratio than did each of the other groups. No other pairwise differences were significant.

To ensure that use of the elevation ratio was appropriate, the mean number of responses in the pre-CS periods for each session (i.e., background response rate) was calculated. These scores were subjected to a two-factor ANOVA (group $\times$ block). This analysis revealed no statistically significant difference between the groups ( $p>$ .30 ); neither was the group $\times$ session interaction significant $(F<1)$. Thus, there were no statistically significant differences in the background rate of responding in this experiment. The mean rates of responding in the pre-CS periods, collapsed over all sessions, were 2.4 for Group $\mathrm{A} / \mathrm{AB}^{\backslash \mathrm{C}}, 2.2$ for Group $\mathrm{A} / \mathrm{AB}^{\mathrm{C}}, 2.2$ for Group $\mathrm{A} / \mathrm{B}^{\backslash \mathrm{C}}$, and 2.9 for Group $\mathrm{A} / \mathrm{B}^{\mathrm{C}}$.

These results replicate those already presented with respect to the influence on enhanced latent inhibition of a salient stimulus presented immediately following a compound stimulus; such a treatment attenuated the enhanced latent inhibition effect. No such attenuation of the effect was noted in a group that received a salient stimulus that was presented randomly with respect to the compound. This result suggests that the attenuation of the enhanced latent effect was not the result of any nonspecific 


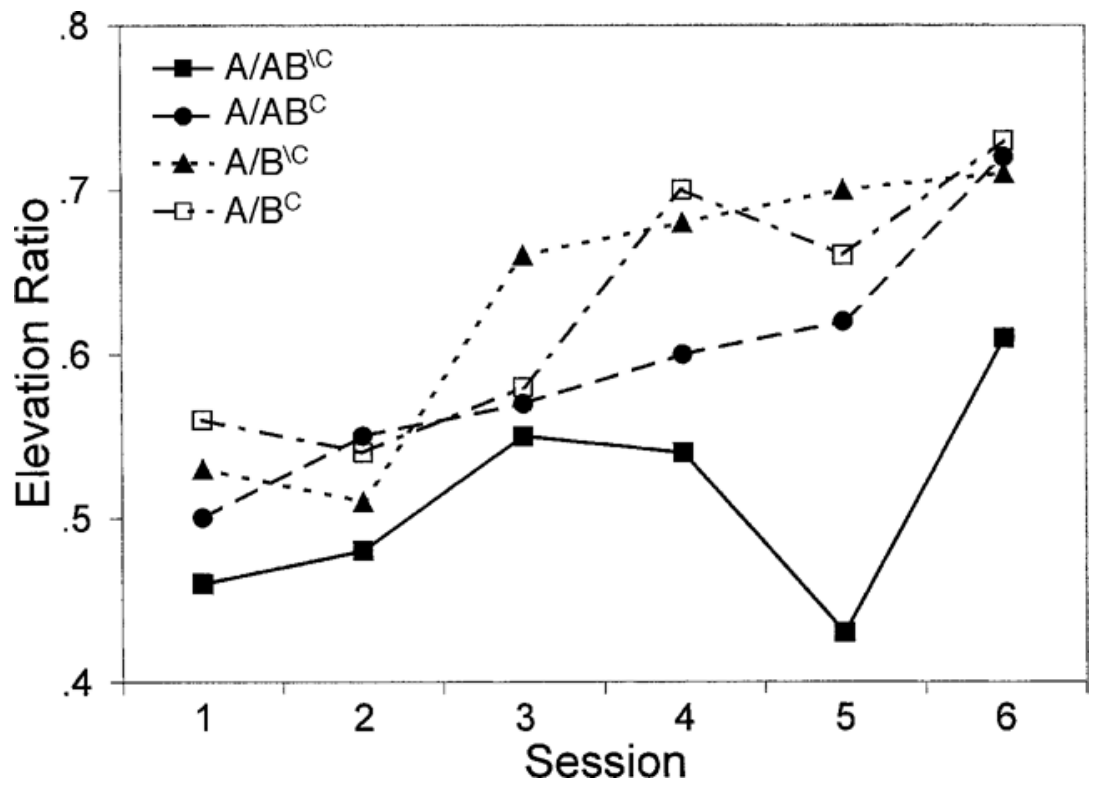

Figure 5. Results from Experiment 5: group-mean elevation ratios averaged over each session. Group $A / A B C$ received exposure to the nontarget stimulus before exposure to a target/nontarget simultaneous compound stimulus, followed by a tone, prior to conditioning. Group $A / A B{ }^{\backslash C}$ received exposure to the nontarget stimulus before exposure to a target/nontarget simultaneous compound stimulus, as well as to ten 2 -sec tones presented randomly with respect to the compound. Group $A / B^{C}$ received exposure to the nontarget stimulus before exposure to a target stimulus, followed by a tone, prior to conditioning. Group $A / B^{\backslash C}$ received exposure to the nontarget stimulus before exposure to a target. Group $\mathrm{A} / \mathrm{AB}^{\mathrm{C}}$ received exposure to the nontarget stimulus before exposure to a target/ nontarget simultaneous compound stimulus, followed by a tone, prior to conditioning. Group $A / A B{ }^{\backslash C}$ received exposure to the nontarget stimulus before exposure to a target/ nontarget simultaneous compound stimulus, as well as to ten $\mathbf{2}$-sec tones presented randomly with respect to the compound.

effects of thep tone (a finding that is also corroborated by the results of Experiment 4, in which a group receiving a delayed tone displayed enhanced latent inhibition).

The results also show that a salient cue presented after the target stimulus alone did not result in any disruption of latent inhibition. Groups $\mathrm{A} / \mathrm{B}^{\mathrm{CC}}$ and $\mathrm{A} / \mathrm{B}^{\mathrm{C}}$ produced identical levels of conditioning to one another, and both produced greater levels of conditioning than did the enhanced latent inhibition group. These results suggest that the salient cue presented after a nonreinforced compound $\mathrm{AB}$ stimulus presentation may well serve to disrupt the formation of within-compound associations and, hence, to limit the growth of an association between the target and no event mediated through the target-nontarget association.

\section{GENERAL DISCUSSION}

Enhanced levels of latent inhibition were generated following a blocking preexposure-that is, exposure to a nonreinforced nontarget stimulus, followed by exposure to a nonreinforced target/nontarget compound. The retardation in conditioning noted after this treatment was greater than that noted when nonreinforced exposure was given to the target alone (Experiment 1) or to the nontarget followed by the target alone (Experiment 2). This effect emerged only when the nontarget member of the compound stimulus had been presented in Phase 1 (Experiment 1) and when the two stimuli were presented in compound with one another, rather than randomly with respect to one another (Experiment 2). These data confirm and extend previous demonstrations of the enhanced latent inhibition effect (see Reed, 1995a, 1995b; Reed et al., 1999; Reed et al., 1997).

One view of this effect assumes that latent inhibition is the result of associative interference (Hall et al., 1985; Killcross \& Balleine, 1996) and that all latent inhibition effects may be explained by invoking standard associative interference principles. For example, during simple nonreinforced preexposure, a stimulus-no-event association is formed that interferes with subsequent stimulus-event learning during conditioning. In the enhanced latent inhibition treatment, during the first phase of the $\mathrm{A}^{0} / \mathrm{AB}^{0}$ preexposure treatment (i.e., $\mathrm{A}^{0}$ ), a nontarget-no-event association is formed. In the compound stimulus exposure phase (i.e., $\mathrm{AB}^{0}$ ), the subjects acquire a target-no-event 
association $(\mathrm{B} \rightarrow 0)$, and also a target-nontarget $(\mathrm{B} \rightarrow \mathrm{A})$ association. The latter association enhances learning about the target and no event through second-order conditioning $(\mathrm{B} \rightarrow \mathrm{A} \rightarrow 0)$ and produces greater latent inhibition than in conditions in which only $\operatorname{direct}(\mathrm{B} \rightarrow 0)$ associations are formed.

In the present experiments, we sought to explore whether such putative second-order stimulus-no-event associations were formed under conditions similar to those for second-order associations involving such events as food. Holland (1980) noted that second-order conditioning was disrupted if a salient event followed the compound stimulus but was not disrupted when no such stimulus occurred. This latter circumstance is precisely that which prevails during compound stimulus preexposure procedures but does not occur in standard conditioning blocking experiments that follow a compound stimulus with a US. This finding suggests a reason that second-order conditioning results in enhanced latent inhibition but does not play such a dominant role in standard conditioning procedures (where the converse effectnamely, blocking - dominates).

If enhanced latent inhibition is based on second-order conditioning of a B-A association, it should be disrupted by a salient stimulus presented immediately after the compound termination. This effect was noted in all of the experiments reported in the present series. Moreover, as in the study reported by Holland (1980), a delay between the termination of the compound stimulus and the presentation of the distractor was found to attenuate the disruptive effect of the latter cue on second-order conditioning (Experiment 4). This was not the result of general disruption caused by the loud tone distractor, since a randomly presented tone distractor in Experiment 5 (as well as a tone presented only a short time following compound offset in Experiment 3) failed to disrupt the enhanced latent inhibition effect.

Taken together, these results are consistent with an associative interference view of latent inhibition and enhanced latent inhibition. They suggest that a simple extension of the laws of association, already documented for event learning (e.g., Holland, 1980), will suffice to explain these stimulus preexposure phenomena. However, there are a couple of important caveats to these suggestions. First, it should be noted that there was no independent assessment of the strength of the within-compound associations in the present experiments. Although the pattern of data supports the within-compound association view of the effects, such an assessment would add strength to the argument.

Second, once it is accepted that second-order conditioning plays a role during stimulus preexposure procedures, this allows that the second-order conditioning could be of inattention, as is suggested by the conditioned attention theory put forward by Lubow (1989). It could be that inattention conditions to the nontarget stimulus (A) during the first phase of the treatment. Inat- tention also will accrue to the target (B) during the compound phase, by both direct conditioning and secondorder conditioning through $\mathrm{A}$. The distractor stimuli may well serve to disrupt this process, as was outlined above. However, it is harder for the conditioned inattention view to explain the extinction of enhanced latent inhibition effects noted by Reed et al. (1997). Similarly, it could be that attentional views could accommodate the present results (e.g., Hall \& Honey, 1988). Presentation of the target in compound with the already habituated nontarget may allow greater attentional processing of the target during the compound stimulus phase than would otherwise have occurred. This would result in greater latent inhibition. The presentation of a salient distractor may disrupt this process and reduce the amounts of latent inhibition to the target. Again, although this account is plausible, it has more difficulty with the extinction of latent inhibition data reported by Reed et al. (1997). Finally, according to the SOP model proposed by Wagner (1981), prior exposure to the nontarget stimulus will allow the formation of a context-nontarget association. Owing to the context's priming the nontarget representation into the A2 memory state, the nontarget will not subsequently disrupt processing of a context-target association in the A1 state. The target will subsequently be primed into A2 by the context, and the formation of a target-US association will be impeded. However, it is unclear how enhanced latent inhibition would be predicted from this view.

An alternate framework in which to discuss these results is suggest by consideration of the Lubow $A-B$ effect (e.g., Lubow et al., 1976). Here, a target stimulus is followed by a second stimulus during preexposure, and the target conditions rapidly after such treatment. Lubow, Weiner, and Schnur (1981) interpret this as a result of the conditioned attention's being maintained to the target as a result of the presence of the second stimulus (although there are other interpretations available; see Kaye, Swietalski, \& Mackintosh, 1988). The present enhanced latent inhibition finding could be considered to be the result of an attenuation of this A-B effect. Prior exposure to the nontarget $(\mathrm{A})$ reduces its ability to maintain attention to the target (B) when they are presented in compound. However, this view does not explain the finding that exposure to $\mathrm{A} / \mathrm{AB}$ results in enhanced latent inhibition, rather than merely attenuating the development of a smaller latent inhibition effect. That is, according to the above $\mathrm{A}-\mathrm{B}$ view, preexposure to A retards its ability to maintain attention to $\mathrm{B}$ in the $\mathrm{AB}$ phase. This should allow latent inhibition to accrue to $\mathrm{B}$ as normal. There were numerous studies reported by Reed et al. (1997) that tested whether the pairing of a new salient distractor with the target would enhance latent inhibition (or retard the A-B effect). None of these was found to be as effective as the enhanced latent inhibition treatment. Finally, one observation reported in Experiment 5 does not concur with this view. When the target stimulus was pre- 
sented alone and was followed by a salient tone, it did not retard the development of latent inhibition, as would be predicted on this view. In fact, this is not the only failure to demonstrate the A-B effect (see Honey \& Hall, 1988). It may well be that the present experiment does not use the appropriate parameters for this effect to be an issue.

Given the above, it is unclear that any other contemporary view of latent inhibition can easily accommodate the entire pattern of results obtained from enhanced latent inhibition procedures. To the extent the modified associative interference view accommodates the data, it seems a plausible candidate as an explanation of stimulus preexposure effects. However, the associative interference view is not without its own problems. It holds that during nonreinforced preexposure, a stimulus-no-event association is formed. Given this, it is unclear why a latent inhibited stimulus does not pass a summation test for conditioned inhibition.

Many of the views proposed for latent inhibition effects can be modified to accommodate most of the data presented in such experiments. However, very few accommodate all of the data without significant change or problems. Irrespective of which, if any, of these views ultimately proves to be correct, it is clear that stimulus preexposure effects appear to be subject to influences highly similar to those for conditioning effects, and any view needs to accommodate both, perhaps within the same terms.

\section{REFERENCES}

Hall, G., \& Honey, R. [C.] (1988). Perceptual and associative learning. In S. B. Klein \& R. R. Mowrer (Eds.), Contemporary learning theories: Pavlovian conditioning and the status of traditional learning theory (pp. 117-147). Hillsdale, NJ: Erlbaum.

Hall, G., Kaye, H., \& Pearce, J. M. (1985). Attention and conditioned inhibition. In R. R. Miller \& N. E. Spear (Eds.), Information processing in animals: Conditioned inhibition (pp. 185-207). Hillsdale, NJ: Erlbaum.
Holland, P. C. (1980). Second-order conditioning with and without unconditioned stimulus presentations. Journal of Experimental Psychology: Animal Behavior Processes, 6, 238-250.

Honey, R. C., \& HALl, G. (1988). Overshadowing and blocking procedures in latent inhibition. Quarterly Journal of Experimental Psychology, 40B, 163-186.

Honey, R. C., \& HAll, G. (1992). CS memory after trace conditioning. Learning \& Motivation, 23, 145-155.

Kaye, H., Swietalski, N., \& Mackintosh, N. J. (1988). Distracter effects on latent inhibition are a consequence of generalisation decrement. Quarterly Journal of Experimental Psychology, 40B, 151-161.

Killcross, S., \& Balleine, B. (1996). Role of primary motivation in stimulus preexposure effects. Journal of Experimental Psychology: Animal Behavior Processes, 22, 32-42.

Lubow, R. E. (1989). Latent inhibition and conditioned attention theory. New York: Cambridge University Press.

Lubow, R. E., Schnur, P., \& Rifkin, B. (1976). Latent inhibition and conditioned attention theory. Journal of Experimental Psychology: Animal Behavior Processes, 2, 163-174.

Lubow, R. E., Weiner, I., \& ScHnur, P. (1981). Conditioned attention theory. In G. H. Bower (Ed.), The psychology of learning and motivation (Vol. 15, pp. 1-49). New York: Academic Press.

REED, P. (1991). Blocking latent inhibition. Bulletin of the Psychonomic Society, 29, 292-294.

REED, P. (1995a). Compound stimulus preexposure effects in an appetitive conditioning procedure. Learning \& Motivation, 26, 1-10.

REED, P. (1995b). Enhanced latent inhibition following compound preexposure. Quarterly Journal of Experimental Psychology, 48B, 3245.

Reed, P., Anderson, E., \& Foster, C. (1999). Modality of stimulus effects in compound preexposure procedures: Associative influences in enhanced latent inhibition. Learning \& Motivation, 30, 35-52.

Reed, P., Petrochilos, P., Upal, N., \& Baum, M. (1997). Extinction of enhanced latent inhibition. Animal Learning \& Behavior, 25, $283-$ 290.

Schmajuk, N. A., Lam, Y.-W., \& Gray, J.-A. (1996). Latent inhibition: A neural network approach. Journal of Experimental Psychology: Animal Behavior Processes, 22, 321-349.

WAGNER, A. R. (1981). SOP: A model of automatic memory processing in animal behavior. In N. E. Spear \& R. R. Miller (Eds.), Information processing in animals: Memory mechanisms (pp. 5-47). Hillsdale, NJ: Erlbaum.

(Manuscript received July 17, 2001;

revision accepted for publication February 27, 2002.) 